Check for updates

Cite this: Chem. Commun., 2019, 55,5950

Received 1st February 2019 Accepted 29th April 2019

DOI: $10.1039 / \mathrm{c} 9 \mathrm{cc} 00965 \mathrm{e}$

rsc.li/chemcomm

\section{Boosting axiality in stable high-coordinate Dy(III) single-molecule magnets $\dagger$}

\author{
Angelos B. Canaj, (D) ${ }^{a}$ Mukesh Kumar Singh, ${ }^{b}$ Emma Regincós Marti, (D) ${ }^{a}$ \\ Marko Damjanović, ${ }^{\text {cd }}$ Claire Wilson, (D) ${ }^{a}$ Oscar Céspedes, ${ }^{e}$ \\ Wolfgang Wernsdorfer, (DD ${ }^{c d}$ Gopalan Rajaraman (D) *b and Mark Murrie (D) *a
}

\begin{abstract}
A new nine-coordinate, air-stable Dy(III) single-ion magnet has been successfully isolated. Our in silico studies demonstrate that through carefully modulating the ligand electronics, the axiality can be boosted to generate $U_{\text {cal }}$ barriers of over $600 \mathrm{~K}$.
\end{abstract}

Single-Molecule Magnets (SMMs) are fascinating molecular systems, which display the ability to block magnetisation via an energy barrier, $U_{\text {eff }}$, resulting in the appearance of magnetic hysteresis of molecular origin. ${ }^{1}$ Importantly, the design of viable SMMs strongly correlates with the control of the coordination environment at the level of a single metal ion. ${ }^{2}$ The use of Dy(III) to generate a strong axial magnetic anisotropy, ${ }^{3}$ a realisation achieved through the vital combination of theory and experiment, has led to a new generation of complexes with impressive energy barriers ${ }^{4}$ and high blocking temperatures ${ }^{5}$ with coercivity up to $80 \mathrm{~K}$ (i.e. above the boiling point of liquid nitrogen). ${ }^{6}$ Potential applications will require not only the ability to function at higher temperatures, but also to be chemically stable in air or when exposed to heat. ${ }^{7}$ However, finding an approach towards coordination environments that promote strong magnetic behaviour in 4 f-SMMs and, at the same time, display robust chemical stability under ambient conditions has only recently begun to be addressed. In this regard, we recently reported two pentagonal bipyramidal Dy(III) single-ion magnets (SMMs containing only one metal ion), $\left[\mathrm{Dy}\left(\mathrm{H}_{2} \mathrm{O}\right)_{5}(\mathrm{HMPA})_{2}\right] \mathrm{Cl}_{3} \cdot \mathrm{HMPA} \cdot \mathrm{H}_{2} \mathrm{O}$ and $\left[\mathrm{Dy}\left(\mathrm{H}_{2} \mathrm{O}\right)_{5}(\mathrm{HMPA})_{2}\right] \mathrm{I}_{3} \cdot 2 \mathrm{HMPA}$ (HMPA = hexamethylphosphoramide), with blocking temperatures

\footnotetext{
${ }^{a}$ WestCHEM, School of Chemistry, University of Glasgow, University Avenue, Glasgow, G12 8QQ, UK. E-mail: mark.murrie@glasgow.ac.uk

${ }^{b}$ Department of Chemistry, Indian Institute of Technology Bombay, Powai, Mumbai, Maharashtra, 400076, India.E-mail: rajaraman@chem.iitb.ac.in

${ }^{c}$ Physikalisches Institut (PHI), Karlsruhe Institute of Technology,

Wolfgang-Gaede-Strasse 1, 76131 Karlsruhe, Germany

${ }^{d}$ Institute of Nanotechnology (INT), Karlsruhe Institute of Technology, Hermann-von-Helmholz-Platz 1, 76344 Eggenstein-Leopoldshafen, Germany

${ }^{e}$ School of Physics and Astronomy, University of Leeds, Leeds LS2 9JT, UK

$\dagger$ Electronic supplementary information (ESI) available: Experimental and computational data; CIFs for 1, 4 and 2 CCDC 1889693-1889695. For ESI and crystallographic data in CIF or other electronic format see DOI: 10.1039/ c9cc00965e
}

of $\sim 10 \mathrm{~K}$, and we emphasized the important role of the second coordination sphere in controlling the magnetisation reversal barrier. ${ }^{8}$ In fact, complexes with higher coordination numbers $(\geq 9)$ that also possess high energy barriers are rare and tuning such an environment in a way that promotes high axiality whilst offering good stability to air, heat and moisture is a challenging task. For this reason, we were intrigued by the complexes $\left[\mathrm{Ln}^{\mathrm{III}} \mathrm{LF}\right]\left(\mathrm{CF}_{3} \mathrm{SO}_{3}\right)_{2} \cdot \mathrm{H}_{2} \mathrm{O} \quad(\mathrm{L}=$ 1,4,7,10-tetrakis(2-pyridylmethyl)1,4,7,10-tetraaza-cyclododecane) and, in particular, the notable absence of the Dy(III) analogue along with the lack of magnetic data on any of the reported complexes. ${ }^{9}$ The Dy ion geometry is extremely important in order to obtain higher blocking temperatures and we reasoned that the combination of the pseudo $D_{4 \mathrm{~d}}\left\{\mathrm{DyN}_{8}\right\}$ cage with a strong axial ligand should show interesting SMM characteristics. ${ }^{10}$ Herein, we report the synthesis, magnetic characterisation and ab initio studies of $\left[\mathrm{Dy}{ }^{\mathrm{III}} \mathrm{LF}\right]\left(\mathrm{CF}_{3} \mathrm{SO}_{3}\right)_{2} \cdot \mathrm{H}_{2} \mathrm{O}(\mathbf{1})$. Furthermore, we demonstrate an elegant strategy for improving the magnetic behaviour of high-coordinate $4 \mathrm{f}$ complexes. By carefully modulating the ligand environment in silico, we show how the calculated energy barrier, $U_{\text {cal }}$, can be increased, thus making 1 an extremely attractive system to probe the effects of the highcoordinate ligand environment on the dynamics of the magnetisation. Compound 1 (Fig. 1 and Fig. S6, S7, ESI $\dagger$ ) was isolated under aerobic conditions from aqueous solution (see ESI $\dagger)^{9}$ and the stability of $\mathbf{1}$ to $\sim 350{ }^{\circ} \mathrm{C}$ is verified by TGA analysis (Fig. S5, ESI $\dagger$ ).

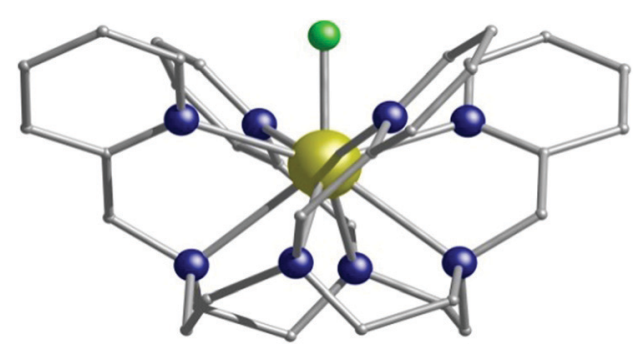

Fig. 1 The structure of 1. Dy, gold; N, blue; F, green; C, grey. Hydrogen atoms, counter-ions and the co-crystallised water molecule are omitted for clarity. 
We also report the isostructural (but not isomorphous) lanthanum analogue, $\left[\mathrm{La}{ }^{\mathrm{III}} \mathrm{LF}\right]\left(\mathrm{CF}_{3} \mathrm{SO}_{3}\right)_{2} \cdot \mathrm{H}_{2} \mathrm{O}$ (2) (Table $\mathrm{S} 1$ and Fig. S1, S2, S11, ESI $\dagger$ ) and the Dy-doped lanthanum analogue (3) (Fig. S4, ESI $\dagger$ ). The nine coordinate Dy(III) centre sits on a $C_{2}$ symmetry axis, coincident with the Dy-F bond. Continuous shape measures analysis, ${ }^{11}$ which estimates the distortion from the perfect polyhedron, gives a value of 1.429 (where 0 corresponds to the ideal structure) for a muffin geometry (Fig. S8 and Tables S4, S5, ESI $\dagger$ ). The ninth coordination site is occupied by a strong electronegative fluoride ion, with a relatively short Dy-F bond length of 2.123(2) $\AA$ (Table S3, ESI $\dagger$ ). Intermolecular hydrogen bonding between the triflate counter-ions and the water molecule is present (Fig. S9, ESI $\dagger$ ). In addition, the $\mathrm{C}-\mathrm{H} \cdots \mathrm{F}$ intermolecular interactions between neighbouring molecules of 1 create a 1D columnar structure along the $c$-axis with the closest Dy. $\cdots$ Dy distance of $7.757 \AA$ (Fig. S10, ESI $\dagger$ ).

For 1, the eight Kramers Doublets (KDs), corresponding to the ${ }^{6} \mathrm{H}_{15 / 2}$ ground state, span an energy range of $808 \mathrm{~K}$ (see ESI $\dagger$ for computational details). The transverse components of the ground state $\left(m_{\mathrm{J}}= \pm 15 / 2\right)$ are found to be negligible $\left(g_{x x}=0.006\right.$, $g_{y y}=0.012$, Table S7, ESI $\dagger$ ), establishing a strong magnetic anisotropy axis $\left(g_{z z}=19.837\right)$, lying along the Dy-F bond (Fig. S28, ESI $\dagger$ ). This can be explained using LoProp ${ }^{12}$ charges computed using the CASSCF wavefunction. The charge on the axial $\mathrm{F}$ atom is found to be nearly three times larger compared to the nitrogen atoms of the cage ligand, (Fig. S28, ESI $\dagger$ ) and this dictates the direction of $g_{z z}$ axis. Similarly, the axial nature is also observed for the first and second exited states $\left(m_{\mathrm{J}}= \pm 13 / 2, g_{x x}=0.212\right.$, $g_{y y}=0.228, g_{z z}=16.800$ and $m_{\mathrm{J}}= \pm 11 / 2, g_{x x}=0.468 g_{y y}=0.583$, $g_{z z}=13.380$, respectively, Table S7, ESI $\dagger$ ), which are found to lie at $185 \mathrm{~K}$ and $381 \mathrm{~K}$, respectively above the ground state. Notably, the larger $g_{x x} / g_{y y}$ values obtained for the third-exited state $\left(m_{\mathrm{J}}= \pm 9 / 2\right.$; $\left.\pm 1 / 2, g_{x x}=5.213 g_{y y}=5.565, g_{z z}=8.350\right)$ yield a larger magnetic moment matrix element of $1.8 \mu_{\mathrm{B}}$ (Fig. 2) which is sufficient to promote magnetic relaxation via this state, giving the maximum calculated relaxation barrier $\left(U_{\text {cal }}\right)$ of $\sim 527 \mathrm{~K}$. It is important to note that a small transverse magnetic moment is calculated for the first three $\operatorname{KDs}\left(3.1 \times 10^{-3}, 7.3 \times 10^{-2}\right.$ and $1.7 \times 10^{-1} \mu_{\mathrm{B}}$, respectively), suggesting the presence of weak Quantum Tunnelling of the Magnetisation (QTM) and again, relaxation via the third exited state. The Orbach processes related to the $m_{\mathrm{J}}$ and $m_{\mathrm{J}}+1$ excited states of opposite magnetization for the first four KDs are found to be very small $(<0.16$, Fig. 2). Furthermore, thorough analysis of the $g$-tensor (Table S7, ESI $\dagger$ ) reveals axiality up to the third excited state (KD4).

The dc magnetic susceptibility measurements for 1 (Fig. S13, $\mathrm{ESI} \dagger$ ) show that the experimental $\chi_{\mathrm{M}} T$ value of $14.1 \mathrm{~cm}^{3} \mathrm{~mol}^{-1} \mathrm{~K}$ (at $300 \mathrm{~K}$ ) is in close agreement with the theoretical value $\left(14.2 \mathrm{~cm}^{3} \mathrm{~mol}^{-1} \mathrm{~K}\right)$ for a single Dy(III) ion $\left({ }^{6} \mathrm{H}_{15 / 2}, S=5 / 2\right.$, $L=5, g=4 / 3)$. Upon cooling, $\chi_{\mathrm{M}} T$ decreases steadily to a value of $11.1 \mathrm{~cm}^{3} \mathrm{~mol}^{-1} \mathrm{~K}$ at $20 \mathrm{~K}$, due to thermal depopulation of the $m_{\mathrm{J}}$ levels, before increasing to $12.0 \mathrm{~cm}^{3} \mathrm{~mol}^{-1} \mathrm{~K}$ at $2.8 \mathrm{~K}$. This low temperature increase is consistent with the presence of weak ferromagnetic intermolecular interactions. Furthermore, the $\chi_{\mathrm{M}} T$ data of the diluted sample 3 instead decreases between $50-2 \mathrm{~K}$, which further supports the hypothesis of weak ferromagnetic

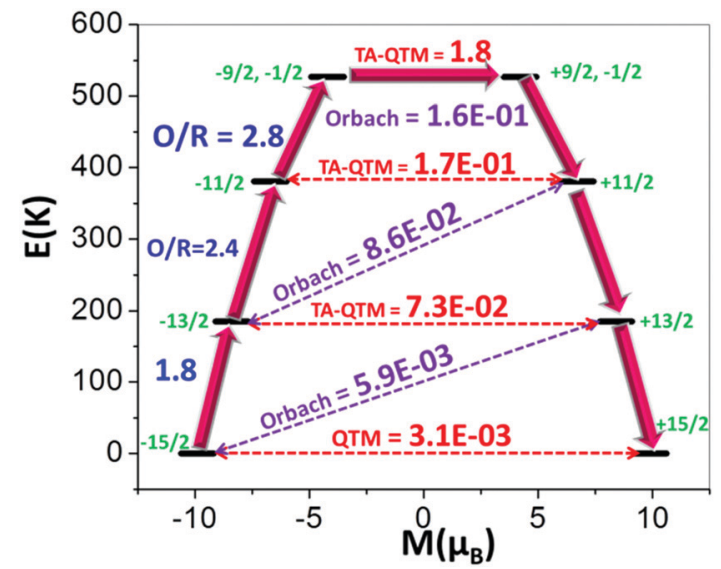

Fig. 2 Ab initio calculated relaxation dynamics for complex 1 . The arrows show the connected energy states with the number representing the matrix element of the transverse moment (see text for details). Here, $\mathrm{QTM}=$ quantum tunnelling of the magnetisation, TA-QTM = thermally assisted QTM, O/R = Orbach/Raman process. The numbers above each arrow represent corresponding transverse matrix elements for the transition magnetic moments.

intermolecular interactions in 1 (Fig. S14, ESI $\dagger$ ). Alternating current (ac) susceptibility measurements between $0.6-800 \mathrm{~Hz}$, under zero external dc field, were performed in order to investigate the dynamics of the magnetisation for $\mathbf{1}$ and the Dy-doped lanthanum analogue, 3. Under zero external dc field, the out-of-phase, $\chi_{M}{ }^{\prime \prime}$ magnetic susceptibility data exhibit welldefined maxima as a function of frequency (Fig. 3 and Fig. S17, $\mathrm{ESI} \dagger$ ) and temperature with $\chi_{\mathrm{M}}{ }^{\prime \prime}$ peaks clearly observable up to $12 \mathrm{~K}$ for 1 (Fig. S15, ESI $\dagger$ ) and up to $20 \mathrm{~K}$ for 3 (Fig. S16, ESI $\dagger$ ).
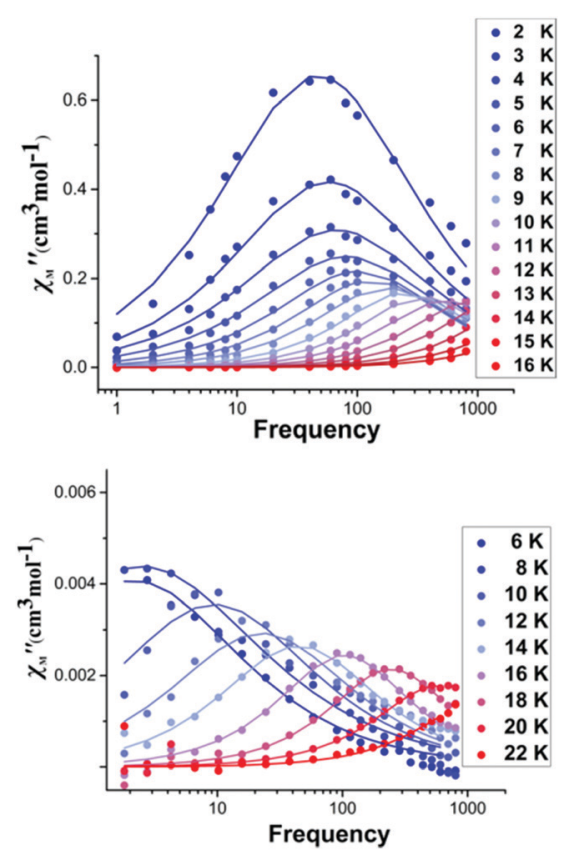

Fig. 3 Frequency dependent out-of-phase ac susceptibility signals for complex $\mathbf{1}$ (upper) and $\mathbf{3}$ (lower) in zero dc field. The solid lines correspond to the best fit. 
For 1 , the plots of $\chi_{M}{ }^{\prime}$ and $\chi_{M}{ }^{\prime \prime} v s$. temperature show a rapid increase in the low temperature region (Fig. S15, ESI $\dagger$ ). Additionally, the low temperature set of peaks in the $\chi_{M}{ }^{\prime \prime}(v)$ curves exhibit little temperature dependence (Fig. 3 upper), which could be attributed to faster relaxation effects (QTM). ${ }^{13}$ For the diluted sample 3, the $\chi_{\mathrm{M}}{ }^{\prime \prime}(T)$ maxima under zero dc field, are shifted to higher temperatures and the signal at lower temperatures is significantly reduced, suggesting a slower relaxation of the magnetisation (Fig. S16, ESI $\dagger$ ). The relaxation times, $\tau$, were extracted from the fit of the Argand plots of $\chi_{M}{ }^{\prime \prime} v s$. $\chi_{M}{ }^{\prime}$ using the generalized Debye model (Fig. S18, ESI $\dagger$ ). ${ }^{14}$ The $\alpha$ parameters found are relatively large in the range of $0.01-0.29(2-13 \mathrm{~K})$ for 1 , and $0.01-0.41$ (6-22 K) for 3, indicating a relatively wide distribution of relaxation times. ${ }^{1}$ Thus, the Arrhenius plots are fitted considering more than one possible relaxation process yielding an energy barrier of $U_{\text {eff }}=\sim 110 \mathrm{~K}$ for 1 (Fig. S19 and Table S9, ESI $\dagger$ ) and $U_{\text {eff }}=\sim 290 \mathrm{~K}$ for the diluted sample 3 (Fig. S20 and Table S9, ESI $\dagger$ ). Importantly, it should be noted that these values are among the highest for high-coordinate lanthanide single-ion magnets (see Table S6, ESI $\dagger$ ). To explore the role of low-lying vibrational levels that could enhance relaxation and lower the $U_{\text {cal }}$ barrier, we analysed the N-Dy-F bending mode which lies at $115 \mathrm{~cm}^{-1}$ (Fig. S29, ESI $\dagger$ ). Calculations performed on selected vibrational modes corresponding to this frequency reveal a significant reduction in the estimated barrier height (see Fig. S29, ESI $\dagger$ ). To assess the strength of the intermolecular interactions, further calculations were performed which yielded small dipolar and intermolecular magnetic exchange couplings $\left(0.02 \mathrm{~cm}^{-1}\right.$ and $0.08 \mathrm{~cm}^{-1}$ respectively). These are expected to further enhance relaxation (see Fig. S30, ESI $\dagger$ ). ${ }^{15}$

Magnetisation $v s$. field hysteresis loops were performed on 1 and 3 in light of the large energy barriers observed. Low-temperature hysteresis studies were performed on a single crystal of 1 using an array of micro-SQUIDs. ${ }^{16}$ The increase in coercivity with decreasing temperature (Fig. 4) and increasing scan rate (Fig. S26, ESI $\dagger$ ) confirms 1 to be a SMM.

The $M$ vs. $H$ loops suggest the presence of QTM and have steps that are somewhat smeared out at low temperatures, possibly due to a distribution of local environments (e.g. disordered solvent molecules, crystals defects) and/or intermolecular interactions. For the diluted powder sample 3 more pronounced butterfly-like

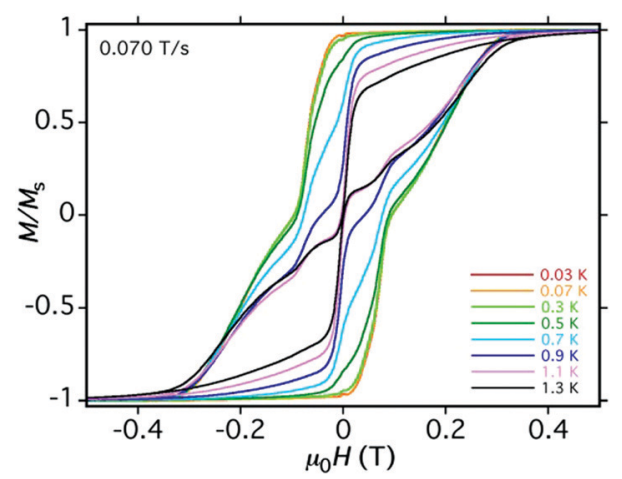

Fig. 4 Temperature dependence of single crystal magnetisation versus field hysteresis loops for 1 . loops are observed until $3 \mathrm{~K}$ (average sweep rate of $\sim 10 \mathrm{mT} \mathrm{s}^{-1}$ ) (Fig. S27, ESI $\dagger$ ). The promising magnetic properties and the high stability of $\mathbf{1}$, combined with the ability to modify either the axial ligand or the polydentate cage ligand, led us to study the effect on the magnetic dynamics of modulating the ligand environment in silico (Fig. 5). To do this, we have created a family of different model systems and used $a b$ initio calculations to show how the ligand electronics can be used to tune and improve the relaxation properties (Fig. S31, S32 and Table S8, ESI $\dagger$ ).

Substitution of the axial $\mathrm{F}^{-}$ion by monodentate formate or substituted carboxylates (models 2-4 Fig. 5) destroys the $U_{\text {cal }}$ barrier. These weaker axial groups reduce the crystal field splitting significantly, leading to smaller barrier heights (Fig. 5 and Fig. S31, ESI $\dagger$ ) and due to smaller charges compared to the nitrogen atoms of the polydentate ligand, the $g_{z z}$ direction changes (Fig. S32, ESI $\dagger$ ). Stronger ligands ( ${ }^{-}$OR, models 1, 5 and 6 Fig. 5) maintain the $g_{z z}$ direction, but with smaller $U_{\text {cal }}$ values than 1. This suggests that axial substitution is detrimental in $\mathbf{1}$ with the $\mathrm{F}^{-}$ion being the most promising, as was recently shown by Norel et al. ${ }^{17}$ We reasoned that if the coordination by the ligand nitrogen atoms is weakened, this should further enhance the barrier height, by moving towards a pseudo Dy-F environment. ${ }^{18}$ Hence, we have substituted the -ortho and -para $\mathrm{H}$ atoms of the pyridinic ring with strong electron withdrawing groups (models 7-9 Fig. 5). For these models, the computed transverse anisotropy (see Table S8, model-7, model-8 and model-9, ESI $\dagger$ ) is found to be significantly reduced, causing an impressive increase to give a $U_{\text {cal }}$ energy barrier of $645 \mathrm{~K}$ (for X = $\mathrm{F}, \mathrm{Z}=\mathrm{F}, \mathrm{Y}=\mathrm{H}$, see Fig. 5).

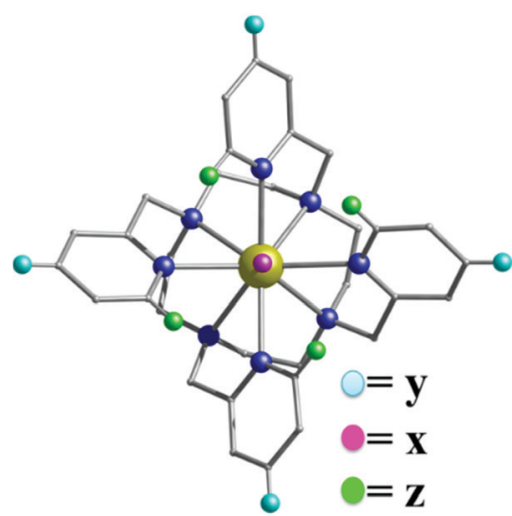

\begin{tabular}{|c|c|c|c|c|}
\hline & $\mathbf{Z}$ & Y & $\mathbf{X}$ & $\mathbf{U}_{\text {cal }}(\mathbf{K})$ \\
\hline 1 & H & H & $F^{-}$ & $527\left(4^{\text {th }} K D\right)$ \\
\hline Model-1 & H & H & $\mathrm{OH}^{-}$ & $371\left(4^{\text {th }} \mathrm{KD}\right)$ \\
\hline Model-2 & $\mathrm{H}$ & H & $\mathrm{HCO}_{2}^{-}$ & $0.0\left(1^{\text {st }} \mathrm{KD}\right)$ \\
\hline Model-3 & $\mathrm{H}$ & $\mathrm{H}$ & ${ }^{t} \mathrm{BuCO}_{2}^{-}$ & $0.0\left(1^{\mathrm{st}} \mathrm{KD}\right)$ \\
\hline Model-4 & $\mathrm{H}$ & H & $\mathrm{CF}_{3} \mathrm{CO}_{2}^{-}$ & $0.0\left(1^{\text {st }} \mathrm{KD}\right)$ \\
\hline Model-5 & $\mathrm{H}$ & $\mathrm{H}$ & $\mathrm{CH}_{3} \mathrm{CH}_{2} \mathrm{CH}_{2} \mathrm{O}^{-}$ & $361\left(4^{\text {th }} \mathrm{KD}\right)$ \\
\hline Model-6 & H & H & ${ }^{t} \mathrm{BuCH}_{2} \mathrm{CH}_{2} \mathrm{O}^{-}$ & $372\left(4^{\text {th }} \mathrm{KD}\right)$ \\
\hline Model-7 & $\mathbf{F}$ & H & $F^{-}$ & 645 (4 $\left.{ }^{\text {th }} K D\right)$ \\
\hline Model-8 & $\mathrm{CN}$ & H & $\mathrm{F}^{-}$ & $576\left(4^{\text {th }} K D\right)$ \\
\hline Model-9 & H & $\mathrm{NO}_{2}$ & $\mathrm{~F}^{-}$ & 571 (4 $\left.4^{\text {th }} K D\right)$ \\
\hline
\end{tabular}

Fig. 5 In silico models based on 1 showing how the $U_{\text {cal }}$ barrier can be increased by tuning the ligand electronics. 
Furthermore, the transverse matrix elements for the transition magnetic moments are reduced (see Fig. S31, ESI $\dagger$ ) and hence the probability of QTM/TA-QTM is decreased. This suggests a promising route to realise higher barriers for magnetization reversal. Importantly, the models investigated were designed taking into consideration their likely future experimental realisation; i.e. they do not show strong steric hindrance and/or have low coordination numbers. To check further the effect of the transverse field we have rotated the $-\mathrm{N}_{4}$ plane by \pm 6 degrees in a model complex (Fig. S33, ESI $\dagger$ ) and in the presence of the strong axial $\mathrm{F}$ ion, changes in the calculated $U_{\text {cal }}$ values are found to be negligible (Fig. S34, ESI $\dagger$ ). Efforts are currently underway to synthesise substituted analogues of the polydentate cage ligand in our laboratory and as a proof-of-concept we also report the crystal structure of a new ligand (Fig. S12 and Table S2, ESI $\dagger$ ) where the electron withdrawing CN group, has been included in the ortho position of each pyridinic ring (Fig. 5 model-8, Fig. S31, S32 and Table S8, ESI $\dagger$ ). Hence, future work will focus on the realisation of the above exciting family of complexes with high energy barriers along with good air and heat stability.

The UK Engineering and Physical Sciences Research Council are thanked for financial support (grant ref. EP/N01331X/1). The data which underpin this work are available at http://dx. doi.org/10.5525/gla.researchdata.789. G. R. thanks the SERB (EMR/2014/00024) for funding. MKS thanks IIT Bombay for a fellowship.

\section{Conflicts of interest}

There are no conflicts to declare.

\section{Notes and references}

1 A. Dey, P. Kalita and V. Chandrasekhar, ACS Omega, 2018, 3, 9462; A. K. Bar, P. Kalita, M. K. Singh, G. Rajaraman and V. Chandrasekhar, Coord. Chem. Rev., 2018, 367, 163; Z. Zhu, M. Guo, X.-L. Li and J. Tang, Coord. Chem. Rev., 2019, 378, 350; M. Feng and M.-L. Tong, Chem. - Eur. J., 2018, 24, 7574; S. G. McAdams, A.-M. Ariciu, A. K. Kostopoulos, J. P. S. Walsh and F. Tuna, Coord. Chem. Rev., 2017, 346, 216; B. M. Day, F.-S. Guo and R. A. Layfield, Acc. Chem. Res., 2018, 51, 1880; S. K. Gupta and R. Murugavel, Chem. Commun., 2018, 54, 3685.

2 L. Sorace, C. Benelli and D. Gatteschi, Chem. Soc. Rev., 2011, 40, 3092; J. Wu, J. Jung, P. Zhang, H. Zhang, J. Tang and B. Le Guennic, Chem. Sci., 2016, 7, 3632; K. Katoh, S. Yamashita, N. Yasuda, Y. Kitagawa, B. K. Breedlove, Y. Nakazawa and M. Yamashita, Angew. Chem., Int. Ed., 2018, 57, 9262; Y.-C. Chen, J.-L. Liu, L. Ungur, J. Liu, Q.-W. Li, L.-F. Wang, Z.-P. Ni, L. F. Chibotaru, X.-M. Chen and M.-L. Tong, J. Am. Chem. Soc., 2016, 138, 2829; J. Liu, Y.-C. Chen, J.-L. Liu, V. Vieru, L. Ungur, J.-H. Jia, L. F. Chibotaru, Y. Lan, W. Wernsdorfer, S. Gao, X.-M. Chen and M.-L. Tong, J. Am. Chem. Soc., 2016, 138, 5441; S. K. Gupta, T. Rajeshkumar, G. Rajaraman and R. Murugavel, Chem. Sci., 2016, 7, 5181.
3 S. T. Liddle and J. van Slageren, Chem. Soc. Rev., 2015, 44, 6655; L. Ungur and L. F. Chibotaru, Phys. Chem. Chem. Phys., 2011, 13, 20086; J. D. Rinehart and J. R. Long, Chem. Sci., 2011, 2, 2078.

4 S.-D. Jiang, B.-W. Wang, H.-L. Sun, Z.-M. Wang and S. Gao, J. Am. Chem. Soc., 2011, 133, 4730; Y.-S. Meng, L. Xu, J. Xiong, Q. Yuan, T. Liu, B. W. Wang and S. Gao, Angew. Chem., Int. Ed., 2018, 57, 1; K. L. M. Harriman, J. L. Brosmer, L. Ungur, P. L. Diaconescu and M. Murugesu, J. Am. Chem. Soc., 2017, 139, 1420; Y.-S. Ding, N. F. Chilton, R. E. P. Winpenny and Y.-Z. Zheng, Angew. Chem., Int. Ed., 2016, 55, 16071; Y.-S. Ding, K.-X. Yu, D. Reta, F. Ortu, R. E. P. Winpenny, Y.-Z. Zheng and N. F. Chilton, Nat. Commun., 2018, 9, 3134; S. Demir, M. I. Gonzalez, L. E. Darago, W. J. Evans and J. R. Long, Nat. Commun., 2017, 8, 2144; M. Gregson, N. F. Chilton, A.-M. Ariciu, F. Tuna, I. F. Crowe, W. Lewis, A. J. Blake, D. Collison, E. J. L. McInnes, R. E. P. Winpenny and S. T. Liddle, Chem. Sci., 2016, 7, 155; P. E. Kazin, M. A. Zykin, V. V. Utochnikova, O. V. Magdysyuk, A. V. Vasiliev, Y. V. Zubavichus, W. Schnelle, C. Felser and M. Jansen, Angew. Chem., Int. Ed., 2017, 56, 1; F. Liu, D. S. Krylov, L. Spree, S. M. Avdoshenko, N. A. Samoylova, M. Rosenkranz, A. Kostanyan, T. Greber, A. U. B. Wolter, B. Buchner and A. A. Popov, Nat. Commun., 2017, 8, 16098.

5 A. P. Goodwin, F. Ortu, D. Reta, N. F. Chilton and D. P. Mills, Nature, 2017, 548, 439; A. P. Goodwin, D. Reta, F. Ortu, N. F. Chilton and D. P. Mills, J. Am. Chem. Soc., 2017, 139(51), 18714; F.-S. Guo, B. M. Day, Y.-C. Chen, M.-L. Tong, A. Mansikkamaki and R. A. Layfield, Angew. Chem., Int. Ed., 2017, 56, 11445; K. R. McClain, C. A. Gould, K. Chakarawet, S. J. Teat, T. J. Groshens, J. R. Long and B. G. Harvey, Chem. Sci., 2018, 9, 8492.

6 F.-S. Guo, B. M. Day, Y.-C. Chen, M.-L. Tong, A. Mansikkamäki and R. A. Layfield, Science, 2018, 362, 1400.

7 R. Vincent, S. Klyatskaya, M. Ruben, W. Wernsdorfer and F. Balestro, Nature, 2012, 488, 357; E. M. Pineda, C. Godfrin, F. Balestro, W. Wernsdorfer and M. Ruben, Chem. Soc. Rev., 2018, 47, 501; C. Godfrin, A. Ferhat, R. Ballou, S. Klyatskaya, M. Ruben, W. Wernsdorfer and F. Balestro, Phys. Rev. Lett., 2017, 119, 187702.

8 A. B. Canaj, M. K. Singh, C. Wilson, G. Rajaraman and M. Murrie, Chem. Commun., 2018, 54, 8273.

9 O. A. Blackburn, A. M. Kenwright, A. R. Jupp, J. M. Goicoechea, P. D. Beer and S. Faulkner, Chem. - Eur. J., 2016, 22, 8929; L. S. Natrajan, N. M. Khoabane, B. L. Dadds, C. A. Muryn, R. G. Pritchard, S. L. Heath, A. M. Kenwright, I. Kuprov and S. Faulkner, Inorg. Chem., 2010, 49, 7700; A. Wada, B. Watanabe, Y. Yamanoi and H. Nishihara, Chem. Commun., 2008, 1671; O. A. Blackburn, N. F. Chilton, K. Keller, C. E. Tait, W. K. Myers, E. J. L. McInnes, A. M. Kenwright, P. D. Beer, C. R. Timmel and S. Faulkner, Angew. Chem., Int. Ed., 2015, 54, 10783; O. A. Blackburn, A. M. Kenwright, P. D. Beer and S. Faulkner, Dalton Trans., 2015, 44, 19509.

10 T. Gupta and G. Rajaraman, Eur. J. Inorg. Chem., 2018, 3402.

11 M. Llunell, D. Casanova, J. Cirera, J. M. Bofill, P. Alemany and S. S. Alvarez, SHAPE (version 2.1), Barcelona, 2013.

12 L. Gagliardi, R. Lindh and G. Karlstrom, J. Chem. Phys., 2004, 121, 4494. 13 J.-L. Liu, Y.-C. Chen and M.-L. Tong, Chem. Soc. Rev., 2018, 47, 2431. 14 D. Gatteschi, R. Sessoli and J. Villain, Molecular Nanomagnets, Oxford Univ. Press, 2006.

15 E. Rousset, M. Piccardo, M.-E. Boulon, R. W. Gable, A. Soncini, L. Sorace and C. Boskovic, Chem. - Eur. J., 2018, 24, 14768.

16 W. Wernsdorfer, Adv. Chem. Phys., 2001, 118, 99; W. Wernsdorfer, Supercond. Sci. Technol., 2009, 22, 064013; W. Wernsdorfer, N. E. Chakov and G. Christou, Phys. Rev. B: Condens. Matter Mater. Phys., 2004, 70, 132413.

17 L. Norel, L. E. Darago, B. L. Guennic, K. Chakarawet, M. I. Gonzalez, J. H. Olshansky, S. Rigaut and J. R. Long, Angew. Chem., Int. Ed., 2018, 57, 1.

18 L. Ungur and L. F. Chibotaru, Inorg. Chem., 2016, 55, 10043. 